\title{
Morphometry of the aortic arch and its branches. A computed tomography angiography-based study
}

\author{
M. Tapia-Nañez'1 , G.A. Landeros-Garcia'1, M.A. Sada-Treviño², R. Pinales-Razo², \\ A. Quiroga-Garza'1, B.A. Fernandez-Rodarte'1, R.E. Elizondo-Omaña'1', S. Guzman-Lopez ${ }^{1}$

\begin{abstract}
${ }^{1 H}$ uman Anatomy Department, School of Medicine, Universidad Autónoma de Nuevo León, Mexico ${ }^{2}$ Radiology and Diagnostic Imagining Department, University Hospital "Dr. José Eleuterio González",
\end{abstract} \\ Universidad Autónoma de Nuevo León, Mexico
}

[Received: 27 May 2020; Accepted: 14 July 2020; Early publication date: 22 August 2020]

Background: The current study aims to determine the prevalence of variations of the aortic arch using computed tomography angiography (CTA), as well as morphometries and gender correlations.

Materials and methods: A retrospective, transverse, observational and descriptive study of 220 CTA was performed. The branching pattern, most cranial vertebral level of the aortic arch, area of the proximal, middle and distal segments of the arch, area of each branch, and the path of atypical arteries were recorded. Results were analysed and stratified by gender.

Results: The typical aortic arch branching pattern was present in $77.7 \%$ without statistical significance between genders. The most common variant was a two-branch pattern with a common trunk and a left subclavian (13.6\%), followed by a typical branching pattern with an added left vertebral artery (7.3\%). T3 was the most frequent cranial level (32.3\%), followed by T2-T3 (26.8\%), and T3-T4 (23.2\%). The mean areas of the aortic arch were $685.5 \pm 183.9$, $476.1 \pm 124.1$, and $445.0 \pm 145.1 \mathrm{~mm}^{2}$ for the proximal, middle and distal segments, with statistical difference between men and women in the middle and distal segments. Three paths of atypical arteries were identified: bifurcated vertebral artery $(0.5 \%)$, aberrant right subclavian artery $(0.5 \%)$, and left subclavian ostium obstruction (0.5\%).

Conclusions: Mexican population has one of the highest prevalence of variations in the aortic arch branching pattern. The high probability of finding these should be taken into consideration when assessing patients. A standardised classification method would contemplate future un-reported findings, without causing confusion by the different numbers assigned by each author. (Folia Morphol 2021; 80, 3: 575-582)

Key words: aortic arch, anatomical variants, branching pattern, Mexico

Address for correspondence: Dr. A. Quiroga-Garza, Departamento de Anatomía Humana, Facultad de Medicina, Universidad Autónoma de Nuevo León, Francisco I. Madero S/N, Mitras Centro, 64460 Monterrey, Nuevo León, México, tel: +52 818329 4171, e-mail: dr.aquirogag@gmail.com 


\section{INTRODUCTION}

The aorta is the main arterial trunk in the human body. It originates as the ascending aorta and becomes the aortic arch, which begins anteriorly and ends posteriorly towards the left in the superior mediastinum, at the transverse thoracic plane (an imaginary plane drawn from the angle of Louis [joint between the manubrium and sternal body] to the mid-point between thoracic vertebrae IV-V) [16].

The aortic arch has a classic branching pattern originating from the superior margin, from right to left: brachiocephalic trunk (BT), left common carotid artery (LCC), and left subclavian artery (LS). This pattern is present in $65-80 \%$ of individuals $[3,13,26]$.

The circulatory system is one of the first systems to be established in the embryo. The primary arterial arches develop from the arterial sac between the $6^{\text {th }}$ and $8^{\text {th }}$ weeks of intrauterine life. The $4^{\text {th }}$ left arch will proceed to become the aortic arch, which will later undergo through exponential growth and join the dorsal aorta. This primary arterial system suffers many changes during its development, and that may constitute one of the causes for the many anatomical variations found in the blood vessels $[13,23]$.

Variations in the branches of the aortic arch have been described in different populations with a prevalence of up to $35 \%[16,26]$. These may repercuss during surgical procedures involving the superior mediastinum and neck, as well as in minimally invasive vascular procedures $[2,16,25]$. Some authors suggest a correlation between variations in the aortic arch and other pathologies such as intracranial aneurysms [22] and plates of atheroma at the level of its origin [28]. Patients with congenital heart disease have been linked to higher variability, presenting the normal 3-branch-pattern in only half (50.5\%) of the cases [24].

Data regarding aortic arch branch variants are scarce in Latin American [19]. The aim of our study was to determine the prevalence of variants of the aortic arch using computed tomography angiography (CTA), as well as morphometries and gender correlations.

\section{MATERIALS AND METHODS}

A retrospective, transverse, comparative, observational study was performed. CTA studies were obtained from the database of the Radiology and Imaging Department at the University Hospital. All images were acquired using a 64-slice tomography (General Electric CT99 Light
Speed VCT) Software 2978195VCT, with a rotation of $0.4 \mathrm{~s}$ helical acquisition, detector coverage of $20 \mathrm{~mm}$, $400 \mathrm{mAs}$ at $120 \mathrm{kV}$; thickness of cut of $0.625 \mathrm{~mm}$, pitch of $0.53: 1 \mathrm{~mm} /$ rot, field of view of 22 to $33 \mathrm{~cm}$.

Studies were included consecutively from adult patients ( $\geq 18$ years old), without gender distinction, and adequate vascular anatomy visualisation. Those with technical errors that distorted the anatomy, had a history of thoracic surgery or vascular procedures, or alteration of the anatomy due to trauma or other pathologies were excluded.

Measurements were performed by an expert radiologist, with aid of an anatomist. Data obtained was transferred and analysed in a Work Station AW Volume Share2 workstation using multiplanar reformatting with maximum projection intensity and rendering volume. During the measurements, a window range of WW: 4000 and WL: 1000 was used in a standardised manner in all the subjects.

The number of arteries originating within the limits of the aortic arch and the branching pattern were classified according to Natsis et al. [17]. The most cranial vertebral level of the aortic arch was recorded, along with the luminal area of the aorta in the proximal, middle, and distal segments (using the transverse thoracic plane) (Fig. 1). For the proximal and distal segments, a line was drawn from the Louis angle (manubriosternal junction) to the midpoint between the inferior edge of T4 and the superior edge of T5 in a sagittal section of the CTA where the entire aortic arch was seen. The area of these segments was measured at the point where this line crossed respectively using the reconstructed transverse thoracic plane in three-dimensional (3D) for the luminal area (adjusting the plane to visualise a completely transverse view of the aortic arch). The cut-off point for the area in the middle segment was the most cranial vertebral level of the aortic arch where the reconstructed 3D plane was also adjusted to view the real area. The area of each branch (measured at its origin's height) originated in the arch of the aorta and the path of the atypical arteries originating in the arch of the aorta were also evaluated.

\section{Statistical analysis}

Sample size was previously calculated based on the variability reported in the literature. This resulted in a sample of 202 individuals with $95 \%$ confidence interval. A total of 220 CTA were included. Data were input into a database. The statistical analysis was car- 


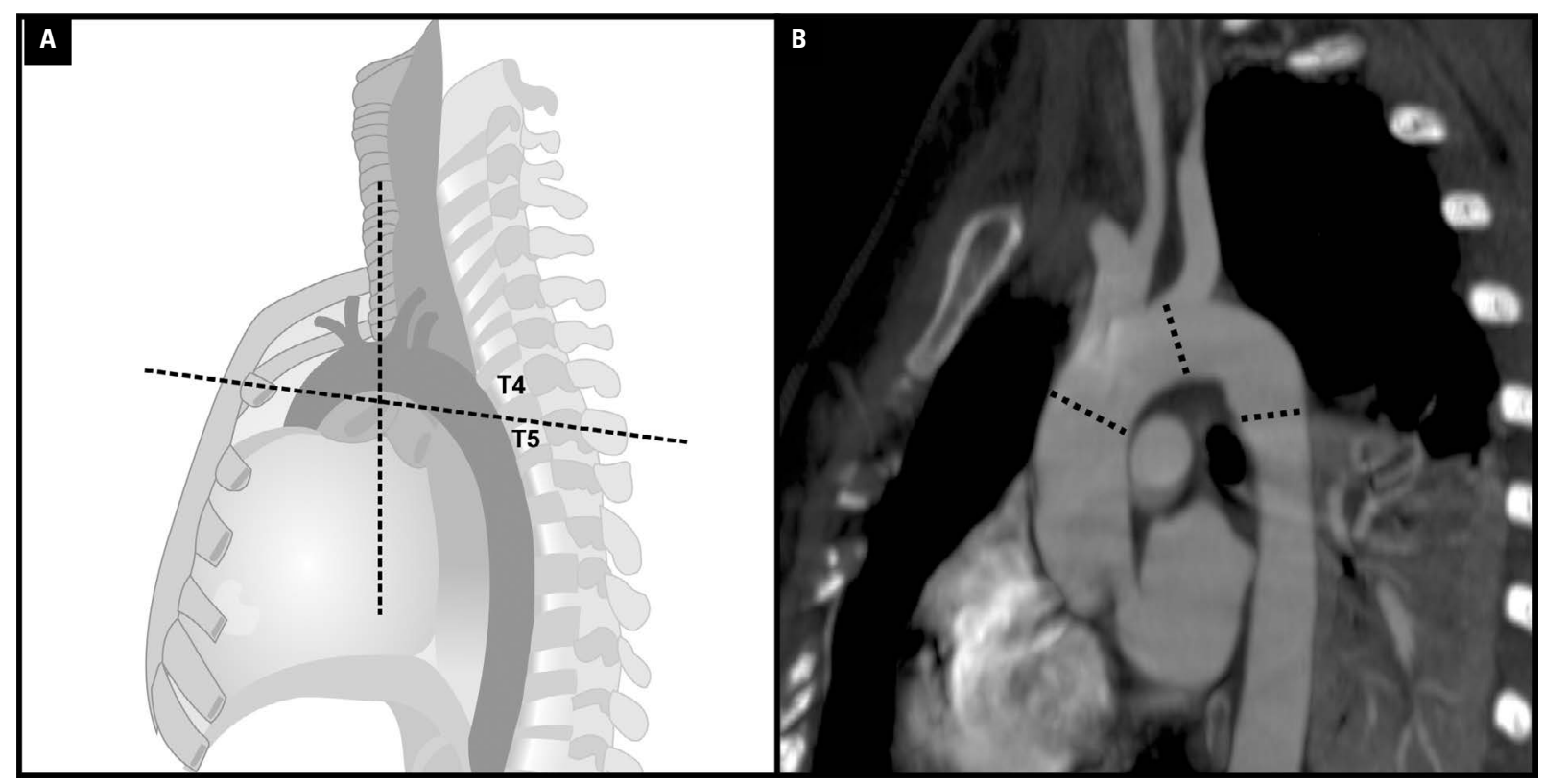

Figure 1. Thorax side view representation; A. Graphic representation of the transverse (Louis angle) and longitudinal (most cranial point of the aortic arch) planes used as the reference to mark the segment where the area of the aortic arch will be measured in its proximal, middle and distal segments; B. Louis angle plotted from the manubrial-sternal joint to the midpoint between the thoracic vertebrae T4 and T5. Cut lines in the proximal, middle and distal segment of the aortic arch in a computed tomography angiography (the inclination of the lines is due to the study adjustment for a correct visualisation of the vessel area).

ried out using the SPSS software version 20.0 (SPSS Inc., Chicago, IL) for Windows XP. Central tendency tests were performed (mean, standard deviation, frequency). Non-parametric tests with Mann-Whitney $\mathrm{U}$ were made to obtain the correlations between genders. Descriptive statistics and measures of central tendency for the prevalence of the evaluated variables were used.

\section{Ethical approval}

The study was previously reviewed and approved by the University's ethics and research committees with the registration number AH17-00007. The authors declare no financial or commercial gain for the realisation of this study. Also, the authors declare no conflict of interest. No patient was radiated for the purposes of this study.

\section{RESULTS}

A total of 220 CTA were included (114 men, and 106 women), with a mean age of $52.7 \pm$ \pm 17.6 years. The classic branching pattern (type 1 ) was the most prevalent $(77.7 \%, \mathrm{n}=171)$. Anatomical variations were present in the remaining $22.3 \%$ $(n=49) ; 13.6 \%(n=30)$ with a type 2 (common trunk [CT], left subclavian [LS]) and 7.3\% ( $\mathrm{n}=16)$ with a type 3 (BT, LCC, left vertebral [LV], and a LS) aortic arch (Fig. 2). Individual cases of type $5(n=1$, $0.5 \%$ ) (right common carotid [RCC], LCC, LS, and aberrant right subclavian [ARS]), type 1 inversus ( $n=1,0.5 \%$ ) (aortic arch to the right: right aortic arch [RAA], BT, LCC, and LS), and an unclassified type or as a proposed type $9(n=1,0.5 \%)(C T, L S$, and LV) were identified (Table 1). The most cranial vertebral level of the aortic arch was obtained using a plane parallel to the transverse thoracic plane (Fig. 1). The majority (82.3\%) were between T2-T4 vertebral levels (Fig. 3), with the highest prevalence at T3 (32.3\%) (Table 2). The mean areas of the proximal, middle and distal segments of the aortic arch were $685.5 \pm 183.9$, $476.1 \pm 124.1$, and $445.0 \pm 145.1 \mathrm{~mm}^{2}$, respectively. Statistical differences between men and women were found in the middle and distal segments (Table 3). There was no statistical difference in the areas according to the branching pattern $(p=0.27, p=0.30$, $p=0.56$ for the proximal, middle, and distal segments, respectively). The morphological characteristics of the branches are shown in Table 4. Three paths of atypical arteries were found: bifurcated vertebral artery $(n=1,0.5 \%)$, aberrant right subclavian artery 


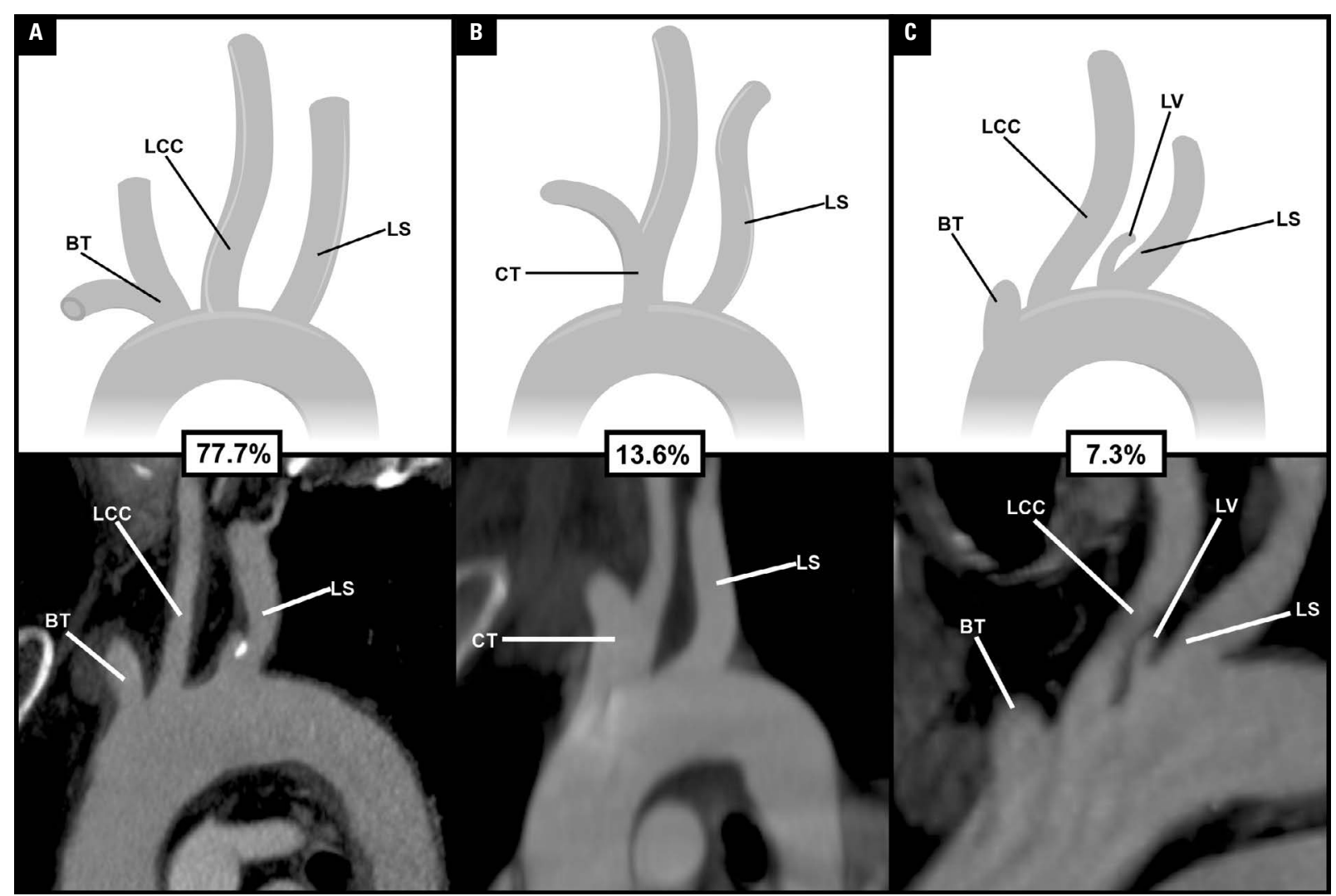

Figure 2. Three most common aortic branching patterns. Upper row demonstrates a graphic representation of the pattern; lower row is a computed tomography angiography slice to demonstrate all branches of the specific pattern; A. Classic branching pattern (type 1); B. Two-branch pattern (type 2); C. Four-branch patter (type 3); BT — brachiocephalic trunk; CT — common trunk; LCC — left common carotid; LS — left subclavian; LV — left vertebral.

Table 1. Branching pattern prevalence

\begin{tabular}{lc}
\hline Branching pattern & $\mathbf{N}(\%)$ \\
\hline BT, LCC, LS & $171(77.7 \%)$ \\
CT, LS & $30(13.6 \%)$ \\
BT, LCC, LV, LS & $16(7.3 \%)$ \\
RCC, LCC, LS, ARS & $1(0.5 \%)$ \\
RAA, BT, LCC, LS & $1(0.5 \%)$ \\
CT, LS, LV & $1(0.5 \%)$ \\
Total & $220(100 \%)$ \\
\hline
\end{tabular}

BT — brachiocephalic trunk; LCC — left common carotid; LS — left subclavian; CT — common trunk; LV — left vertebral; RCC — right common carotid; LV — left vertebral; ARS — aberrant right subclavian; RAA — right aortic arch; $\mathrm{N}$ - sample

( $n=1,0.5 \%)$ and ostium obstruction left subclavian artery $(n=1,0.5 \%)$.

\section{DISCUSSION}

The prevalence of classic aortic arch branching pattern in a Mexican population is similar to that reported in the literature, although anatomical variations were higher than most populations (Table 5)
$[3,7,11,12,16,17,21,27]$. There are only two other studies that include Latin populations, one performed with imaging in a Peruvian population [9] with similar results to our study. A cadaver-based Argentinian study focused on correlating variations to atheroma, concluding a common trunk had a higher incidence of atheroma plaques, therefore a possible increased risk of thromboembolism in clinical scenarios [28]. Three other studies carried out in Colombia, reporting anatomical variations of $25.71 \%, 28.7 \%$, and $40.1 \%[8,20,21]$. The latter with a similar prevalence to ours.

The importance of these variations extends not only to surgical procedures of the superior mediastinum, but also neck, as well as minimally invasive intravascular procedures [18]. For example, right trans-radial coronary angiogram becomes difficult to do satisfactorily with the presence of the right aberrant subclavian artery, increasing the time of the angiogram, increasing manipulation (therefore the risk of intramural hematomas), decreasing the success of the procedure $(60 \%)$, and the number of catheters 


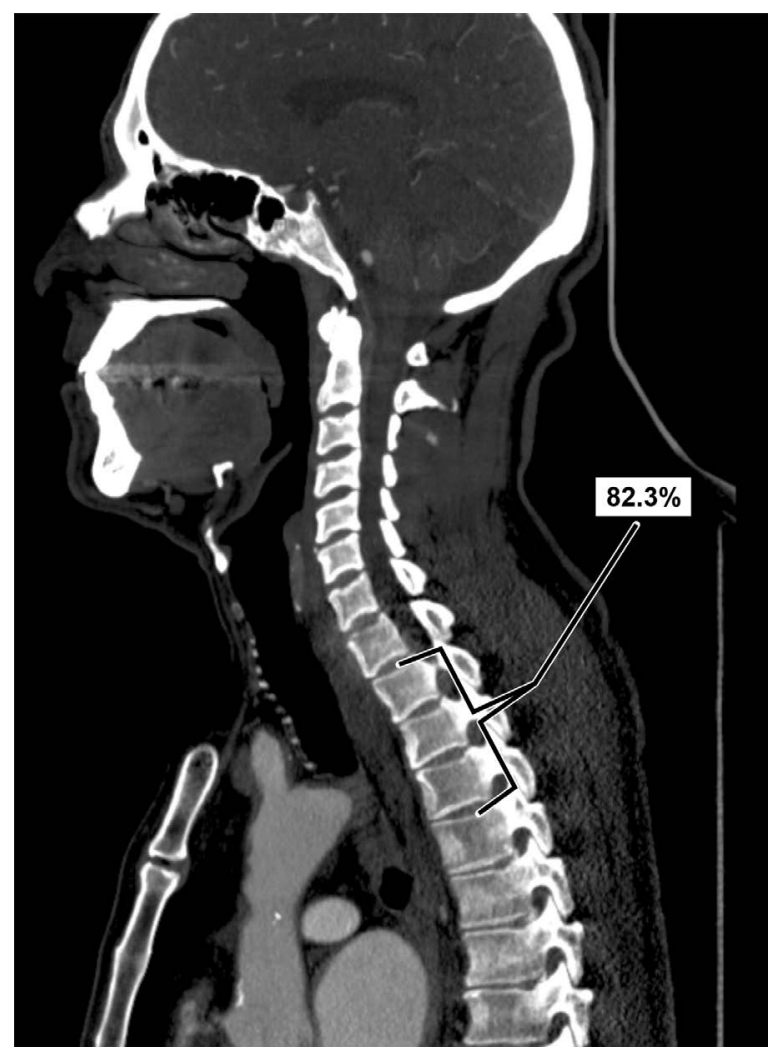

Figure 3. Most cranial level of the aortic arch. The bracket shows that $82.3 \%$ of the most cranial level of the aortic arch will be located in that area (T2-T4).

Table 2. Most cranial vertebral level of the superior border of the aortic arch

\begin{tabular}{lc}
\hline Vertebral level & Prevalence, $\mathbf{n}(\%)$ \\
\hline T1 & $1(0.5 \%)$ \\
T1-T2 & $0(0.0 \%)$ \\
T2 & $9(4.1 \%)$ \\
T2-T3 & $59(26.8 \%)$ \\
T3 & $71(32.3 \%)$ \\
T3-T4 & $51(23.2 \%)$ \\
T4 & $23(10.5 \%)$ \\
T4-T5 & $6(2.7 \%)$ \\
\hline
\end{tabular}

$\mathrm{n}$ - sample

needed $[2,10,25]$. These problems occur especially when the presence of this anatomical variant is unknown [2]. Identification of these may reduce the risk of complications such as haemorrhages [16]. Other studies suggest these anatomical variations may be related to other pathologies such as intracranial aneurysms, higher prevalence of thoracic aortic disease, of bicuspid aortic valve, and aortic arch pathology, although lower risk of arterial hypertension [6, 22]. It has been shown that patients with bovine arch pattern required medical attention at younger ages along with rapid disease progression and an increased need for surgical intervention, along with a higher prevalence of aortic aneurysm and dissections [13].

A two-branch (type 2, CT and LS) variation was the most common variation (13.6\%), similar to most, but significantly lower than United States (24.6\%), Colombia (27.9\%) and Jordan (31.6\%) [6, 16, 20]. This was followed by the four-branch pattern (type 3, BT, LCC, LV, and LS), which was one of the highest (7.3\%), surpassed by India (8\%, 15.3\%) $[4,18]$ and Colombia (8.2\%, 8.5\%, 9.9\%) [8, 20, 21] (Table 5).

A direct relationship between the branch's origin area and the branching pattern was evident in our results. The fewer the branches, the higher the area of origin in each, and vice versa (Table 4).

Using the classification proposed by Natsis et al. [17], types IV-VIII are rarely reported. In our study, one other variant of branching was identified. Great variation according to classification or nomenclature is shown in the literature of the aortic arch branch; each author reports a different classification or classifies the patterns according to their findings, generating confusion when referring to a specific pattern. This is the case with the Natsis type 2 branching pattern (BT, LS); other authors mention it as: type $B$, pattern $C$, bovine pattern and type IIA $[1,5,6,18]$. In the case of the Natsis type 3 (BT, LCC, LS, LV), it has also been referred to as type $D$, type $\mathrm{VI}$, and type 4 [14, 16, 26]. The Natsis type 5 (RCC, LCC, LS, ARS) has been identified as type $F$, pattern $E$, type $D$, type $H$, type $6 \mathrm{~b}$, and so on with all reported variants $[1,5$, $12,15,16]$. A standardisation of branching pattern classification is necessary to contemplate unclassified findings, easy understanding by the readers without having to memorize the types, and avoid confusion between studies, to better compare results in future evidence-based analysis.

Our study has several strengths. A previous sample size calculation was performed to assure significance of our findings. It includes morphological variations not previously described, such as the most cranial point of the aortic arch and its comparison with the vertebral level, although this was limited by the supine decubitus position of the patient during the study, and not taken in an anatomical position. No other study has reported this data. We also compared the prevalence of variations in Table 5. Due to 
Table 3. Aortic arch areas compared between genders

\begin{tabular}{lcccc}
\hline & Mean & Men & Women & P \\
\hline Proximal & $685.5 \pm 183.9$ & $708.4 \pm 198.4$ & $660.9 \pm 164.2$ & 0.05 \\
Middle & $476.1 \pm 124.1$ & $493.3 \pm 127.8$ & $456.6 \pm 117.6$ & $0.02^{*}$ \\
Distal & $445.0 \pm 145.1$ & $466.5 \pm 151.0$ & $421.9 \pm 135.4$ & $0.02^{*}$ \\
\hline
\end{tabular}

Values expressed in $\mathrm{mm}^{2}$ (millimetres squared); *Statistically significant difference. T-test was used for independent samples, compared to gender. Values expressed in squared millimeters \pm standard deviation. Statistically significant $p$ value $<0.05$.

Table 4. Morphological characteristics of the branches

\begin{tabular}{|c|c|c|c|c|c|c|c|c|}
\hline & \multicolumn{8}{|c|}{ Areas, mean \pm standard deviation $\left[\mathrm{mm}^{2}\right]$} \\
\hline & \multirow[t]{2}{*}{ BT } & \multirow[t]{2}{*}{ LCC } & \multirow[t]{2}{*}{ LS } & \multirow[t]{2}{*}{ CT } & \multirow[t]{2}{*}{ LV } & \multicolumn{3}{|c|}{ Aortic arch } \\
\hline & & & & & & Proximal & Medial & Distal \\
\hline Overall $(n=220)$ & $128.3 \pm 47.8$ & $58.0 \pm 24.9$ & $92.3 \pm 27.6$ & $399.5 \pm 599.7$ & $14.1 \pm 6.7$ & $685.5 \pm 183.9$ & $476.1 \pm 124.1$ & $445.0 \pm 145.1$ \\
\hline Type 1 (n = 171) & $129.8 \pm 48.3$ & $58.6 \pm 25.5$ & $92.1 \pm 27.4$ & DNR & DNR & $675.1 \pm 181.5$ & $470.2 \pm 120.2$ & $440.9( \pm 147.3$ \\
\hline Type 2 ( $n=30)$ & DNR & DNR & $109.3 \pm 45.8$ & $401.6 \pm 609.9$ & DNR & $733.8 \pm 210.5$ & $507.2 \pm 138.0$ & $468.5 \pm 136.0$ \\
\hline Type $3(n=16)$ & $114.2 \pm 42.6$ & $50.2 \pm 17.7$ & $59.7 \pm 28.1$ & DNR & $13.2 \pm 5.7$ & $689.9 \pm 162.7$ & $463.4 \pm 138.2$ & $426.6 \pm 143.1$ \\
\hline
\end{tabular}

Type 1 - three-branch pattern; Type 2 - two-branch pattern; Type 3 - four-branch pattern; BT — brachiocephalic trunk; LCC — left common carotid; LS — left subclavian; CT — common trunk; LV — left vertebral; DNR — data no reported

Table 5. Prevalence of anatomical variants in different populations

\begin{tabular}{|c|c|c|c|c|c|c|}
\hline Author (country, year) & Study & Sample (n) & Type 1 & $\begin{array}{c}\text { Anatomical } \\
\text { variations }\end{array}$ & $\begin{array}{l}\text { Two-branch } \\
\text { pattern }\end{array}$ & $\begin{array}{c}\text { Four-branch } \\
\text { pattern }\end{array}$ \\
\hline Grande et al. (Portugal, 1995) & Cad & 33 & $82 \%$ & $18 \%$ & DNR & DNR \\
\hline Natsis et al. (Greece, 2009) & DSA & 633 & $83 \%$ & $17 \%$ & $15 \%$ & $0.79 \%$ \\
\hline Alsaif et al. (Saudi Arabia, 2010) & Cad & 30 & $75 \%$ & $25 \%$ & $16.5 \%$ & $5.5 \%$ \\
\hline Jakanani et al. (UK, 2010) & CT & 861 & $74 \%$ & $26 \%$ & $20 \%$ & $6 \%$ \\
\hline Müller et al. (Germany, 2011) & CTA & 2033 & $86.7 \%$ & $13.3 \%$ & $8 \%$ & $4.1 \%$ \\
\hline Patil et al. (India, 2012) & Cad & 75 & $77.3 \%$ & $22.66 \%$ & $14.66 \%$ & $8 \%$ \\
\hline Ortiz et al. (Colombia 2012) & Cad & 122 & $71.3 \%$ & $28.7 \%$ & $17.2 \%$ & $8.2 \%$ \\
\hline Budhiraja, et al. (India, 2013) & Cad & 52 & $36.5 \%$ & $63.5 \%$ & $19.2 \%$ & $15.3 \%$ \\
\hline Karacan et al. (Turkey, 2014) & CTA & 1000 & $79.2 \%$ & $20.8 \%$ & $14.1 \%$ & $4.1 \%$ \\
\hline Lale et al. (Turkey, 2014) & CTA & 881 & $87.4 \%$ & $12.6 \%$ & $7.2 \%$ & $2.8 \%$ \\
\hline Huapaya et al. (Peru 2015) & CTA & 361 & $78.1 \%$ & $21.9 \%$ & $11.3 \%$ & $2.2 \%$ \\
\hline Dumfarth et al. (USA, 2015) & CT & 556 & $66.5 \%$ & $33.5 \%$ & $24.6 \%$ & $6.3 \%$ \\
\hline Tapia et al. (China, 2015) & CT & 525 & $76.68 \%$ & $23.32 \%$ & $11.8 \%$ & $4.85 \%$ \\
\hline Jalali et al. (Iran, 2016) & MRA & 226 & $84.9 \%$ & $15.1 \%$ & $12.4 \%$ & $0.9 \%$ \\
\hline Mustafa et al. (Jordan, 2016) & CTA & 500 & $61.2 \%$ & $38.8 \%$ & $31.6 \%$ & $5 \%$ \\
\hline Wang et al. (China, 2016) & CT & 2370 & $83.8 \%$ & $16.2 \%$ & $10.24 \%$ & $4.95 \%$ \\
\hline Prada et al. (Colombia, 2016) & CTA & 444 & $59.9 \%$ & $40.1 \%$ & $27.9 \%$ & $9.9 \%$ \\
\hline Rojas et al. (Colombia, 2017) & Cad & 35 & $74.29 \%$ & $25.71 \%$ & $11.43 \%$ & $8.57 \%$ \\
\hline Tapia-Nañez et al. (Mexico, 2020) & CTA & 220 & $77.7 \%$ & $22.3 \%$ & $13.6 \%$ & $7.3 \%$ \\
\hline
\end{tabular}

Cad — cadaveric; CT — computed tomography; CTA — computed tomography angiography; MRA — magnetic resonance angiography; DSA — digital subtraction angiographies; DNR — data no reported 
the retrospective design of our study, findings were not correlated to the clinical history of patients. The presence of dyslipidaemia as well as atherosclerotic lesions can significantly affect the area of blood vessels. Measurements were performed by an expert radiologist and anatomist at the same time, without an interobserver index calculation. Although the sample was obtained from a large reference centre for the northeastern part of Mexico, it is not representative of all Mexican populations, due to the ethnical difference between regions in the country. Standardisation of branch classification has not been obtained, with differences between types, making result comparison difficult.

\section{CONCLUSIONS}

There is a high prevalence $(22.3 \%)$ of anatomic variants in the aortic arch. We report a variant unclassified by Natsis et al. [17]. The luminal areas in the proximal, middle, and distal segments of the aortic arch are bigger in men than in women, with statistical difference in the middle and distal segments. Most (82.3\%) aortic arches are within T2-T4 vertebral level. These should be taken into consideration when evaluating patients for vascular or mediastinal procedures.

\section{Acknowledgements}

Doctor Neri Alejandro Alvarez-Villalobos, Doctor Alejandro Diaz Gonzalez-Colmenero and Doctor Francisco J. Barrera-Flores of the Department of Statistics at the INVEST incubator of the Faculty of Medicine of the Universidad Autonoma de Nuevo Leon for their technical assistance in the realisation of this study.

Conflict of interest: None declared

\section{REFERENCES}

1. Acar M, Ulusoy M, Zararsiz I, et al. Anatomical variations in the branching of human aortic arch. Biomed Res India. 2013; 24(4): 531-535.

2. Allen $D$, Bews $H$, Vo $M$, et al. Arteria lusoria: an anomalous finding during right transradial coronary intervention. Case Rep Cardiol. 2016; 2016: 8079856, doi: 10.1155/2016/8079856, indexed in Pubmed: 27478652.

3. Alsaif $\mathrm{H}$, Ramadan W. An anatomical study of the aortic arch variations. JKAU Med Sci. 2010; 17(2): 37-54, doi: 10.4197/med.17-2.4.

4. Budhiraja V, Rastogi $R$, Jain $V$, et al. Anatomical variations in the branching pattern of human aortic arch: a cadaveric study from central India. ISRN Anat. 2013; 2013: 828969, doi: 10.5402/2013/828969, indexed in Pubmed: 25938106.
5. De Garis CF, Black IH, Riemenschneider EA. Patterns of the aortic arch in american white and negro stocks, with comparative notes on certain other mammals. J Anat. 1933; 67(Pt 4): 599-619, indexed in Pubmed: 17104452.

6. Dumfarth J, Chou AS, Ziganshin BA, et al. Atypical aortic arch branching variants: A novel marker for thoracic aortic disease. J Thorac Cardiovasc Surg. 2015; 149(6): 1586-1592, doi: 10.1016/j.jtcvs.2015.02.019, indexed in Pubmed: 25802134.

7. Grande NR, Costa eS, Pereira AS, et al. Variations in the anatomical organization of the human aortic arch. A study in a Portuguese population. Bull Assoc Anat (Nancy). 1995; 79(244): 19-22.

8. Herrera Ortiz NE, Ballesteros Acuña LE, Forero Porras PL. Caracterizacion de las Ramas del Arco Aórtico en una Muestra de Poblacion Colombiana: Un Estudio con Material de Autopsia. Int J Morphol. 2012; 30(1): 49-55, doi: 10.4067/s0717-95022012000100008.

9. Huapaya JA, Chávez-Trujillo K, Trelles M, et al. Anatomic variations of the branches of the aortic arch in a Peruvian population. Medwave. 2015; 15(6): e6194, doi: 10.5867/ medwave.2015.06.6194, indexed in Pubmed: 26248156.

10. Isser HS, Garg G. Arteria lusoria: A challenge for transradial coronary interventionist. IHJ Cardiovascular Case Reports (CVCR). 2020; 4(1): 7-9, doi: 10.1016/j.ihjccr.2020.04.003.

11. Jakanani GC, Adair W. Frequency of variations in aortic arch anatomy depicted on multidetector CT. Clin Radiol. 2010; 65(6): 481-487, doi: 10.1016/j.crad.2010.02.003, indexed in Pubmed: 20451016.

12. Jalali Kondori B, Asadi MH, Rahimian E, et al. Anatomical variations in aortic arch branching pattern. Arch Iran Med. 2016; 19(1): 72-74, doi: 0161901/AIM.0013, indexed in Pubmed: 26702752.

13. Kahn C, MacNeil M, Fanola C, et al. Complex arterial patterning in an anatomical donor. Transl Res Anat. 2018; 12: 11-19, doi: 10.1016/j.tria.2018.06.001.

14. Makhanya NZ, Mamogale RT, Khan N. Variants of the left aortic arch branches. S Afr J Radiol. 2004; 8(4): 10, doi: 10.4102/sajr.v8i4.102.

15. McDonald J, Anson B. Variations in the origin of arteries derived from the aortic arch, in American whites and negroes. Am J Phys Anthropol. 1940; 27(1): 91-107, doi: 10.1002/ajpa.1330270129.

16. Mustafa AG, Allouh MZ, Ghaida JH, et al. Branching patterns of the aortic arch: a computed tomography angiography-based study. Surg Radiol Anat. 2017; 39(3): 235-242, doi: 10.1007/s00276-016-1720-z, indexed in Pubmed: 27338939.

17. Natsis KI, Tsitouridis IA, Didagelos MV, et al. Anatomical variations in the branches of the human aortic arch in 633 angiographies: clinical significance and literature review. Surg Radiol Anat. 2009; 31(5): 319-323, doi: 10.1007/ s00276-008-0442-2, indexed in Pubmed: 19034377.

18. Patil ST, Meshram MM, Kamdi NY, et al. Study on branching pattern of aortic arch in Indian. Anat Cell Biol. 2012; 45(3): 203-206, doi: 10.5115/acb.2012.45.3.203, indexed in Pubmed: 23094209.

19. Popieluszko P, Henry BM, Sanna B, et al. A systematic review and meta-analysis of variations in branching patterns of the adult aortic arch. J Vasc Surg. 2018; 68(1): 298-306.e10, doi: 10.1016/j.jvs.2017.06.097, indexed in Pubmed: 28865978. 
20. Prada G, Granados AM, Calle JS, et al. Anatomic variations of the aortic arch depicted on $444 \mathrm{CT}$ angiographies. Eur J Anat. 2016; 20(2): 137-141.

21. Rojas M, Muete W, Quijano Y. Anatomical variations of the aortic arch in a sample of Colombian population. Revista de la Facultad de Medicina. 2017; 65(1): 49-54, doi: 10.15446/revfacmed.v65n1.56046.

22. Shiva Kumar GL, Pamidi N, Somayaji SN, et al. Anomalous branching pattern of the aortic arch and its clinical applications. Singapore Med J. 2010; 51(11): e182-e183, indexed in Pubmed: 21140104.

23. St Gielecki J, Wilk R, Syc B. Digital-image analysis of the aortic arch's development and its variations. Folia Morphol. 2004; 63: 449-454, indexed in Pubmed: 15712142.

24. Tawfik AM, Sobh DM, Ashamallah GA, et al. Prevalence and types of aortic arch variants and anomalies in congenital heart diseases. Acad Radiol. 2019; 26(7): 930-936, doi: 10.1016/j.acra.2018.08.023, indexed in Pubmed: 30266547.

25. Valsecchi O, Vassileva A, Musumeci G, et al. Failure of transradial approach during coronary interventions: anatomic considerations. Catheter Cardiovasc Interv. 2006; 67(6): 870-878, doi: 10.1002/ccd.20732, indexed in Pubmed: 16649233.

26. Vučurević G, Marinković S, Puškaš L, et al. Anatomy and radiology of the variations of aortic arch branches in 1,266 patients. Folia Morphol. 2013; 72(2): 113-122, doi: 10.5603/fm.2013.0019, indexed in Pubmed: 23740497.

27. Wang L, Zhang J, Xin S. Morphologic features of the aortic arch and its branches in the adult Chinese population. J Vasc Surg. 2016; 64(6): 1602-1608.e1, doi: 10.1016/j. jvs.2016.05.092, indexed in Pubmed: 27590535.

28. Yeri L, Gómez J, Fontaneto S, et al. Variation of the origin of aortic arch branches: in relationship with plates of atheroma. Int J Morphol. 2011; 29(1): 182-186, doi: 10.4067/ s0717-95022011000100031. 